\title{
ANALISIS STRATEGI PENGELOLAAN MANGROVE MENGGUNAKAN METODE PERBANDINGAN EKSPONENSIAL DI KOTA SORONG PAPUA BARAT
}

\section{ANALYSIS OF MANGROVE MANAGEMENT STRATEGY USING EXPONENTIAL COMPARISON METHODS IN SORONG CITY OF WEST PAPUA}

\author{
Yetty S, Serkadifa ${ }^{1)}$, J. M. Matinahoru ${ }^{2)}$, D.V. Pattimahu ${ }^{2)}$ \\ 1. Jurusan Kehutanan Fakultas Pertanian Unvic Kota Sorong \\ 2,3 Jurusan Kehutanan Fakultas Pertanian Unpatti Ambon \\ Penulis korespondensi e-mail: siskayetty7@ gmail.com
}

\begin{tabular}{l|l} 
Diterima : 3 November 2017 & Disetujui : 5 Desember 2017
\end{tabular}

\section{Intisari}

Manfaat ekosistem mangrove sangat beraneka ragam baik dilihat dari aspek ekologi, ekonomi, sosial dan fungsi perlindungan. Hutan mangrove dapat ditemukan disepanjang pesisir pantai Kota Sorong, ketebalan hutan mangrove yang bervariasi dengan total luasan mangrove pada lokasi penelitian 101 ha, dilihat dari kondisi terkini maka diperlukan strategi dalam pengelolaan mangrove, dengan tujuan dapat menganalisis strategi prioritas pengelolaan mangrove. Kemudian di analisis menggunakan metode perbandingan eksponensial (MPE), dari hasil penelitian menjukan bahwa analisis stretegi pengelolaan mangrove yang diprioritaskan, dari faktor yang pengaruhi yaitu ekologi besar $45.54 \%$, dan dari aktor yang berperan dalam pengelolaan hutan mangrove yaitu pemerintah sebesar $50.89 \%$. Sehingga strategi prioritas dalam pengelolaan yaitu menetapkan rencana pengelolaan dan rencana aksi dalam pengelolaan mangrove sebesar $32,84 \%$.

Kata Kunci : hutan mangrove, metode perbandingan eksponensial

\section{Abstract}

The Benefits of mangrove ecosystems are varied, it can be seen from the ecological aspect, economic , social and protection functions. Mangrove forests can be found along the coastal area of Sorong city, the density of the mangrove forests forest are variaed with the total mangrove area on site research $101 \mathrm{ha}$, current conditions shows that it is necessarily need a strategy in management mangrove, with the aim of priority strategies can analyze mangrove management. Then in the analysis using the method of comparison of the exponential (MPE), menjukan that the research results from the analysis of the stretegi mangrove management developments, of the factors that influence that is a major ecological $45.54 \%$, and of the actor who portrays in the management of mangrove forests that is the Government amounting to $50.89 \%$. So the priority strategy in the management of controlling management plan and a plan of action in the management of mangroves of $32.84 \%$..

Keywords: Mangrove forest, The method of comparison of the exponential

\section{PENDAHULUAN}

Indonesi merupakan salah satu negara yang memiliki hutan mangrove terluas dan terdapat keanekaragaman jenis yang tinggi, terdapat 202 jenis yang terdiri dari 89 jenis pohon, 5 jenis palem, 19 jenis liana dan 44 jenis epifit. Ekosistem hutan mangrove memiliki produktifitas yang tinggi, produktifitas ekosistem mangrove bersekitar 400 - 500 gram karbon $/ \mathrm{m}^{2} /$ tahun adalah tujuh kali lebih produktif dari ekosistem perairan pantai lainnya (Ahmad suryono,2008). Mangrove tumbuh sebagai ekosistem hutan, dengan system perakarannya yang khas terutama tumbuh pada patai dan muara muara sungai berlumpur yang dipengaruhi 
kadar garam dan pasng surut air laut yang tinggi. Manfaat ekosistem mangrove sangat beraneka ragam baik dilihat dari aspek ekologi, ekonomi, sosial dan fungsi perlindungan. Namun, kerusakan hutan mangrove terus meningkat karena pertumbuhan penduduk dan pembangunan yang mengabaikan peran mangrove bagi lingkungannya atau pengaruh naiknya paras laut dan kekuatan abrasi.

Hutan mangrove dapat ditemukan disepanjang pesisir pantai Kota Sorong, ketebalan hutan mangrove yang bervariasi dengan total luasan sebesar 1.651 ha ( Kementrian Perikanan dan Kelautan Kota Sorong, 2012 ). Pada Kelurahan Klasabi dan Kelurahan Kladufu Kota Sorong masih memiliki hutan mangrove dengan luas kawasan pada daerah penelitian sebesar 101 ha (data citra landsat, 2018). Adanya kerusakan yang terjadi akibat pemanfaatan yang berlebihan dari kawasan mangrove, telah menjadi perhatian pemerintah seperti yang telah dilakukan oleh Kesatuan Pengelolaan

\section{METODE PENELITIAN}

Penelitian dilaksanakan di Desa Hulaliu Kecamatan Pulau Haruku

\section{Metode Pengumpulan Data}

Penelitian ini dilaksananakan pada dua kelurahan yaitu Kelurahan Klasabi dan Kelurahan Kladufu Kota Sorong Propinsi
Hutan dan Lahan (KPHL) dalam menyediakan bibit dengan jumlah bibit sebanyak 18.500, UPT Loka Pengelolaan Sumberdaya Pesisir dan Laut (PSPL) dengan penyediaan jumlah bibit sebanyak 10.000, Yayasan mange - mange (LSM) dengan menyediakan jumlah bibit 3.200, dan Dinas Kelautan dan Perikanan Kota Sorong dengan jumlah bibit 500. melalui kegiatan penyedian bibit dari masing masing instansi dan juga melalui kebun bibit rakyat sukri malaso (KBR).

sehingga peran dari setiap stakeholder sangat diperlukan dalam menunjang pelaksaan pengelolaan kawasan mangrove yang berkelanjutan khusunya pada daerah mangrove Kota Sorong. Dengan melihat kondisi lingkungan dan karakteristik sosial, ekonomi masayarakat yang berada disekitar kawasan mangrove, maka diperlukan strategi dalam pengelolaan mangrove yang berkelanjutan. Tujuan dalam penelitian ini adalah menganisis stretegi prioritas pengelolaan hutan mangrove yang berkelanjutan di Kota Sorong.

Kabupaten Maluku Tengah Provinsi Maluku pada bulan April - Mei 2018.

Papua Barat. Pengumpulan data primer dilakukan melalui pengamatan langsung di lapangan, menggunakan kuisioner dan melakukan wawancara langsung pada masyarakat yang berdomisili sekitar 
kawasan mangrove. Pengumpulan data sekunder dengan cara mengumpulkan dokumen - dokumen hasil studi / penelitian sebelumnya, PERDA rencana tata ruang dan yang berkaitan dengan pengelolaan kawasan mangrove, laporan - laporan yang berasal dari instansi terkait metode analisis data yang digunakan dalam penelitian berupa analisis kuantitatif.

Dalam menentukan $\begin{aligned} & \text { strategi } \\ & \text { pengelolaan } \\ & \text { digunakan }\end{aligned}$ metode
perbandingan eksponensial (MPE), metode
perbandingan eksponensial digunakan
untuk menganalisis strategi pengelolaan
yang mempengaruhi dalam pegelolaan
hutan mangrove dengan kriteria yaitu
ekologi, ekonomi, sosial dan aktor yang
berperan dalam pengelolaan hutan
mangrove yaitu pemerintah, masyarakat,
LSM, peneliti di Kota Sorong. Sehingga
dapat menentukan strategi prioritas dalam
pengelolaan mangrove dengan
mengidentifikasi kriteria - kriteria yang
dapat dipakai untuk menetukan strategi
pengelolaan hutan mangrove yang ada di
kota sorong.

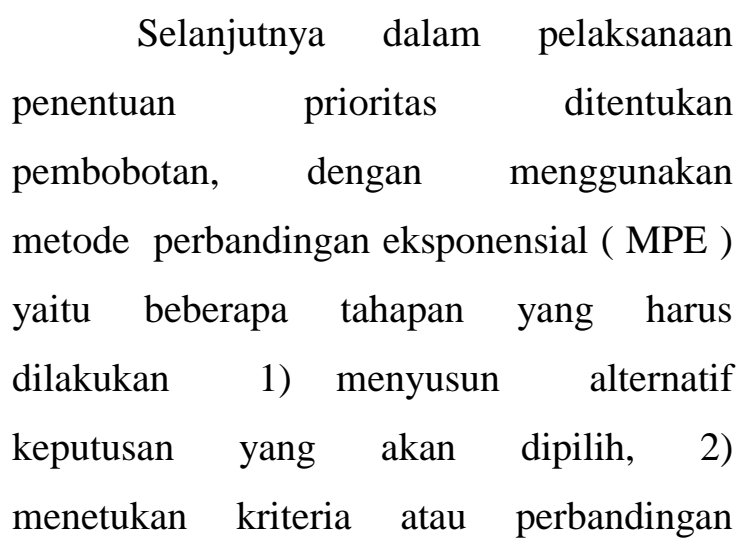

kriteria keputusan yang penting untuk dievaluasi, 3) menentukan tingkat kepentingan dari setiap kriteria keputusan atau pertimbangan kriteria, 4) melakukan penilaian terhadap semua pada setiap kriteria, 5) menghitung skor atau nilai total setiap alternatif, 6) dan menetukan urutan prioritas keputusan didasarkan pada skor atau nilai total masing - masing alternatif.

\section{HASIL DAN PEMBAHASAN}

Bromley (1998) menyatakan terdapat paling tidak empat razim kepemilikan yaitu akses terbuka, negara, swasta, dan masyarakat. Ekosistem mangrove yang ada di Kelurahan Klasabi dan Kelurahan Kladufuk berada pada kepemilikan pemerintah kota , yang dikelola oleh pemerintah daerah. Pada masa yang akan datang, masyarakat diharapkan dapat berperan menjadi key players dalam artian yang positif terhadap keberadaan mangrove, yang dapat dicapai melalui proses penyuluhan dan program pemberdayaan melalui peningkatan kapasitas masyarakat. Hal ini terkait dengan perubahan peran dari LSM dan Lembaga Penelitian yang semula hanya menjadi Crowds menjadi context setters melalui berbagai kegiatan pemberdayaan masyarakat maupun melalui kemampuannya untuk menyuarakan pentingnya penyelamatan hutan mangrove di Kota Sorong. 
Pengelolaan hutan mangrove yang melibatkan banyak pihak dengan berbagai kepentingan sebagaimana yang terjadi di Kota Sorong mengharuskan adanya pembagian peran yang jelas antar para pihak sehingga dapat mencegah terjadinya perilaku yang merugikan. Perilaku seperti mementingkan diri sendiri, pencari keuntungan serta perilaku memanfaatkan kesempatan apabila tidak dikendalikan akan mengakibatkan bertambahnya kerusakan ekosistem kawasan mangrove.

Problem mendasar yang mengancam kerusakan lingkungan, yaitu besarnya ketidaklestarian (unsustainability) sumberdaya alam. Seringkali mengalami kesulitan dalam implementasi kebijakan konservasi dan pembangunan berkelanjutan terutama, banyak dibatasi oleh faktor pemahaman dan kapasitas para pelaksana maupun pengambil kebijakan. Oleh karena itu diperlukan pendekatan pengelolaan secara terpadu dari berbagai sektor stekeholder (Pemerintah, LSM, Peneliti, Swasta dan Masyarakat ) dalam mengupayakan pelestarian kawasam mangrove yang keberlanjutan. Penelitian alternative pada setiap kriteria menggunakan skla penilaian 1-9, dapat dilihat pada Tabel 1.

Tabel 1. Analisis pembobotan dalam strategi pengelolaan hutan mangrove

\begin{tabular}{|c|c|c|c|c|c|}
\hline \multirow[t]{2}{*}{ No } & \multirow{2}{*}{ Kriteria } & \multirow{2}{*}{ Bobot } & \multicolumn{3}{|c|}{ Alternatif pengelolaan mangrove } \\
\hline & & & Ekologi & Ekonomi & Sosial \\
\hline 1 & $\begin{array}{l}\text { Perubahan penutupan } \\
\text { hutan mangrove }\end{array}$ & 7 & 7 & 8 & 7 \\
\hline 2 & Pendapatan masyarakat & 8 & 7 & 8 & 7 \\
\hline 3 & Pengetahuan masyarakat & 7 & 8 & 7 & 7 \\
\hline 4 & Mata pencaharian & 9 & 9 & 8 & 7 \\
\hline 5 & Persepsi masyarakat & 8 & 7 & 7 & 8 \\
\hline 6 & Kebijakan pemerintah & 9 & 7 & 8 & 7 \\
\hline 7 & $\begin{array}{l}\text { Pola hubungan antar } \\
\text { stekholder }\end{array}$ & 9 & 9 & 7 & 8 \\
\hline
\end{tabular}

Sumber : Data primer diolah (2018)

Setelah dihitung menggunakan teknik MPE maka akan terlihat urutan prioritas yang tinggi dari faktor dan aktor yang berperan dalam pengelolaan kawasan mangrove, dapat dilahat pada tabel 2 faktor dalam pengelolaan kawasan mangrove. 
Tabel 2. Faktor yang mempengaruhi dalam pengelolaan mangrove

\begin{tabular}{clccc}
\hline No & Faktor & Prioritas & Nilai MPE & Persentase \\
\hline 1 & Ekologi & 1 & $480,966,882$ & 45.54 \\
2 & Ekonomi & 2 & $334,251,775$ & 31,65 \\
3 & Sosial & 3 & $240,826,488$ & 22,81 \\
\hline
\end{tabular}

Sumber : Data Primer diolah (2018)

Tabel 3. Aktor yang berperan dalam pengelolaan kawasan mangrove

\begin{tabular}{ccccc}
\hline No & Aktor & Prioritas & Nilai MPE & Persentase (\%) \\
\hline 1 & Pemerintah & 1 & $841,930,906$ & 50,89 \\
2 & Masyarakat & 2 & $353,525,384$ & 21,38 \\
3 & LSM & 3 & $323,239,360$ & 19,54 \\
4 & Peneliti & 4 & $135,511,118$ & 8,19 \\
\hline
\end{tabular}

Sumber : Data primer diolah (2018)

Dari perhitungan menggunakan MPE disimpulkan bahwa nilai alternatif pengelolaan mangrove dimana faktor yang paling mempengaruhi yaitu faktor ekologi dengan nilai sebesar 45,54\%, ekonomi berada pada tingkat kedua dengan nilai $31,65 \%$, dan diikuti oleh sosial 22,81\%. sehingga dapat dilihat bahwa tingkat ekologi masih diprioritaskan oleh masyarakat sekitar kawasan mangrove. dapat dilihat alternatif pengelolaan kawasan mangrove dimana aktor yang paling berperan yaitu pemerintah sebesar $50,89 \%$, dan ikuti oleh masyarakat sebesar $21,38 \%$, LSM 19,54 \%, dan peneliti $8,19 \%$. Sehingga dapat dilihat peran pemerintah masih dominan dalam kegiatan pengelolaan hutan mangrove.

Penentuan prioritas pengelolaan hutan mangrove Kota Sorong didasarkan pada kajian terhadap kondisi lingkungan mangrove, kondisi ekonomi, dan sosial masyarakat dan juga pertimbangan dari perangkat kebijakan berupa PERDA yang diberlakukan di Kota Sorong.

Dari hasil perhitungan dengan MPE maka diperoleh Strategi prioritas dimana rencana aksi dalam pengelolaan hutan mangrove yang diprioritaskan dengan nilai sebesar $32,84 \%$. ini menjadi bukti bahwa peran pemerintah berjalan dengan baik karena adanya peraturan daerah yang mengatur pengelolaan kawasan mangrove. Kebijakan penegelolaan ekosistem mangrove dilaksanakan secara terpadu dengan memperhatikan fungsi daerah asuhan bagi sumberdaya ikan, tata ruang, keterlibatan masyarakat dengan tetap melindungi keragaman jenis mangrove, menghidari percepatan penurunan ketersediaan hutan mangrove dan melarang penebangan pada kawasan lindung. Jenis - jenis vegetasi mangrove yang menjadi sasaran dalam pengelolaan meliputi jenis api - api (Avicennia alba), Bakau gandul (Rhizophora mueronata), 
bakau kacangan (Rhizophora opiculata),

gymnorrhiza), tanjan

(Mezzetia dungun (Hiriteria spp), nipah (Nypa parviflora), nyirih (Xyclocarpus granatum) fruticans), tancang (Bruguiera dan nyuruh (Ceriops tagal).

Tabel 4. Prioritas strategi dalam pengelolaan

\begin{tabular}{llcc}
\hline No & \multicolumn{1}{c}{ Strategi pengelolaan } & Skor nilai & persentase \\
\hline 1 & $\begin{array}{l}\text { Menetapkan rencana pengelolaan } \\
\text { dan rencana aksi dalam pengelolaan } \\
\text { mangrove. }\end{array}$ & $877,115,674$ & 32,84 \\
2 & $\begin{array}{l}\text { Memperkuat kapasitas masyarakat } \\
\text { melalui pendidikan lingkungan hidup }\end{array}$ & $853,539,283$ & 31,95 \\
3 & $\begin{array}{l}\text { Meningkatkan koordinasi antara } \\
\text { stakeholders dalam pengelolaan } \\
\text { mangrove berkelajutan 500,539,283 }\end{array}$ & 18,74 \\
$4 \quad \begin{array}{l}\text { Meningkatkan persepsi masyarakat } \\
\text { dalam pengelolaan kawasan } \\
\text { mangrove berkelanjutan } \\
\text { Mengembangkan kegiatan ekonomi } \\
\text { alternati untuk mengurangi } \\
\text { ketergantungan masyarakat terhadap } \\
\text { mangrove }\end{array}$ & 160,001,516 & 10,48 \\
\hline Sumber : Data primer diolah (2018) & 5,99
\end{tabular}

Adanya pelestarian terhadap untuk menghasilkan sumberdaya hutan ekosistem mangrove, akan menjamin terciptanya pemanfaatan yang berlanjut sehingga pembangunan yang berkelanjutan (Sustainnable defelopment) dapat terwujud. pengelolaan yang melibatkan seluruh sektor mempunyai peranan dalam menentukan kesejahtraan di waktu sekarang dan dimasa yang akan datan. Dalam udang - udang No. 23 tahun 1991, pembangunan berkelanjutan harus berwawasan lingkungan hidup, diaman upaya dalam memadukan kemampuan, kesejahtraan dan mutu hidup yang dilandaskan berwawasan lingkungan untuk generasi masa kini dan generasi masa depan. Oleh sebab itu didalam pengelolaan hutan mangrove diperlukan berbagai strategi mangrove dalam pemanfaatan yang berkelanjutan.

Strategi yang dilaksanakan memiliki program - program untuk diterapkan. program - program yang di laksanakan oleh seluruh sektor harus dapat menyelesaikan setiap permasalahan yang terjadi pada hutan mangrove, adapaun strategi - strategi adalah; (1) Meningatkan upaya konservasi mangrove melalui rehabilitasii dan pengayaan ; (2) Memperkuat kapasitas masyarakat melalui pendidikan lingkungan hidup untuk anak usia dini dan anak usia 9-12 tahun, serta kerja sama dari pemerintah untuk meningkatkan kerajinan lokal dari masyarakat sekitar 
hutan mangrove; (3) Meningkatkan keasadaran masyarkat sosialisasi tentang arti pentingnya hutan mangrove dengan mengadakan pelatihan pembuatan bahan

\section{KESIMPULAN}

Strategi pengelolaan keberlanjutan di Kota Sorong yang diprioritaskan dari segi faktor yaitu faktor ekologi, ekonomi, dan sosial dan peran dari stakeholder yang merupakan aktor yang paling berperan dalam pengelolaan hutan mangrove di Kota Sorong yaitu pemerintah, dan diikuti oleh masyarakat, LSM, dan peneliti. Strategi pengelolaan yang diprioritaskan yaitu menetapkan rencana pengelolaan dan

\section{DAFTAR PUSTAKA}

Alikodra H,S. 2012. Konservasi Sumberdaya Alam dan Lingkungan

BAPEDA Kota Sorong, 2014-2013. Rencana Tata Ruang ((RTRW),

Bengen, DG. 2004. Pedoman Teknis Pengenalan dan Pengelolaan Ekosistem

Dahuri, R. 2003. Keanekaragaman Hayati Laut. Aset Pembangunan Berkelanjutan Indonesia. Gramedia Pustaka Utama. Jakarta 412 hlm.

dan Pengelolaannya. INRR Org. Bogor. 189 hlm.

Fandeli, Utami, Nurmansya, 2017. Audit Lingkungan, Gadja Mada University.

INRR, 2005. Delta Mahakam Dalam Ruang dan Waktu. Ekosistem, Sumberdaya

Ir.A.G, kartasaputra, SH, dkk. Teknologi Konservasi Tanah dan Air

Irwan, Z,D.2003. Prinsip-Prinsip Ekologi, Ekosistem, Lingkungan dan pelestariannya. makanan dan minuman dari tumbuhan mangrove; (4) Mengembangkan koordinasi antar stekholder dalam pengelolaan hutan mangrove.

rencana aksi dalam pengelolaan mangrove, memperkuat kapasitas masyarakat melalui pendidikan lingkungan hidup, meningkatkan koordinasi antara stakeholders dalam pengelolaan mangrove berkelajutan, meningkatkan persepsi masyarakat dalam pengelolaan kawasan mangrove berkelanjutan, mengembangkan kegiatan ekonomi alternati untuk mengurangi ketergantungan masyarakat terhadap mangrove.

Langgeng Wahyu S, Tjahyo Nugroho A, Agus Joko P, Agus S. 2014. Kajian Lingkungan Hidup Strategi (KLHS) Kabupten Baggai Kepulauan. Gadja Mada University.

Mangrove. PKSPL. Institut Pertanian Bogor. 60 hlm

OECD, 2001. Sustainable Development: Critical Issues.OECD Pub.,Paris

Pattimahu, D,V. 2010. Kebijakan Pengelolaan Hutan Mangrove Berkelanjutan Kabupaten Seram Bagian Barat Maluku . Disertasi., Program Pascasarjana. Institut Pertanian Bogor, Bogor.

Salampessy, N, S. 2013. Anlisis Kebijakan Pengelolaan Ekosistem Mangrove Kota Ambon. Universitas Pattimura Ambon.

Supriharyono,2009. Konservasi Ekosistem SumberDaya Hayati. di wiyalah Pesisir dan laut tropis

Suryono A.2008. Sukses Usaha Pembibitan Mangrove, Mangrove sang Penyelamat Pulau. 
Tabalessy, R,R. Wantasen, A,S. Scahaduw, J,N,W. 2013. Analisis prioritas pengelolaan ekosistem mangrove menggunakan metode Analysis Hierarchy Process (AHP) di Kota Sorong, Papua Barat, Indonesia. Program magister Ilmu Perairan,
Pascasarjana, Universitas Sam

Ratulangi Manado Sulaweis Utara Indonesia.

URL,http://blog.cifor.org/31191/mangroveindonesia-berkas-faktakekayaannasional dalam-ancaman. 